\title{
Dignity in knowledge
}

\section{Informing patients with Alzheimer's disease about their diagnosis}

\author{
R. A. Clafferty
}

\begin{abstract}
Alzheimer's disease is an emotive lllness surrounded by ethical dilemmas (Burns \& Harris, 1996). One area of increasing concern is the difficulty of telling a patient with Alzheimer's disease of their diagnosis. With the hope of a better understanding of the disease's aetiology (Katzman \& Jackson, 1991), the development of biological markers (Lovestone \& Harper, 1994), the promise of new forms of treatment (Rogers \& Freidhoff, 1996) and research findings suggesting that cognitive decline can be slowed by mental activity (Orrell \& Sahakian, 1995), the issue is likely to gain increasing importance over the next few years. In this paper, the topic is explored in terms of medical ethics, research findings and clinical issues.
\end{abstract}

\section{Ethical principles}

Patients have a right to be involved in decisions about their health care. This presumes that they have the mental capacity to make such judgements. Doctors have a duty not to deceive their patients, and to impart information to them in a form that is understandable to them. Medical interventions must balance the risk of causing harm against the possible benefits (Raanan. 1994).

\section{Research findings}

Research in this field is difficult to perform in view of its sensitive nature and the problems of obtaining informed consent from potential subjects who, by the nature of their disease, may have some degree of mental impairment. It is possible, however, to draw conclusions based on research with patients who suffer from other illnesses. Although cancer is a diverse collection of illnesses (and some forms are curable), several parallels can be drawn between patients with cancer and patients with Alzheimer's disease (Drickamer \& Lachs, 1992). Both groups of patients have life-threatening illnesses of a progressive nature, both have a latent period before onset of illness and eventual death, both give the prospect of increasing dependence and neither have a clearly defined prognosis.

A recent survey of cancer patients demonstrated that $96 \%$ of the sample wanted to be informed of their diagnosis. The majority also wanted information about treatment options and possible side-effects (Meredith et al, 1996).

A study performed with the help of patients who did not have evidence of cognitive decline showed that $90 \%$ of the group would wish to be told of a diagnosis of Alzheimer's disease even though they felt that the news would be distressing (Erde et al, 1988). A second study involving relatives of patients with Alzheimer's disease revealed that $71 \%$ would want to be told if they themselves developed the disease, although only $17 \%$ stated that they wished their own relative to be told (Maguire et al, 1996).

Studies into the practice of doctors in telling patients with cancer their diagnosis have shown a change in practice. In the early 1960s it was shown that $90 \%$ of physicians did not tell their patients with cancer of the diagnosis (Oken. 1961). A major change of opinion was demonstrated when a subsequent survey showed that only $10 \%$ of physicians did not tell patients their diagnosis (Novack, 1979).

In a recent survey of consultant psychiatrists working in Scotland, only $44 \%$ stated that it was their normal practice to inform a patient in the early stages of dementia of their diagnosis (Clafferty et al, 1998). Other surveys have demonstrated a wide variation in psychiatric practice regarding this issue (Rice \& Warner, 1994; Gilliard \& Gwilliam, 1996).

The suggestion from the above research is that most patients with terminal illness want to be told their diagnosis, but that for patients with Alzheimer's disease there is a reluctance on the part of relatives and doctors to provide it.

\section{The case for telling}

There are a number of reasons why it may be important to tell patients their diagnosis. When a doctor is able to break the bad news sensitively to a patient, then the relationship between them 
is likely to be enhanced. Patients may, therefore, be expected to engage more willingly in the medical services. Patient advocate groups are indicating their members wishes to be told their diagnosis (Fearnley et al, 1997) and, in a culture where patients are encouraged to be involved at all stages in decisions about their health care (Department of Health, 1992), doctors cannot be complacent about this issue.

Patients and relatives may already have some suspicions about the meaning of early symptoms, and evasion of the topic may only heighten their anxieties. Confirmation of their fears may allow some relief and give them the ability to face future decisions with dignity. They may take the opportunity to put their affairs in order and make practical arrangements for their future care while they still have the mental capacity to do so (Meyers, 1997). They may make plans for their housing needs and can make enquiries regarding benefit entitlement. They may also wish to consider writing a will and an advance directive to give instructions as to how they wish to be treated at a time when they are less capable of making informed decisions about their care. In the early stages of the illness, they may give informed consent for a trial on drug treatment or for involvement in research (Orrell \& Sahakian, 1995).

\section{The case against telling}

Some doctors may feel that it is best not to tell a patient that they have a disease for which there is no known curative treatment, in the belief that doing so may induce a feeling of hopelessness, a catastrophic reaction or even suicide (Rohde et al, 1995). The nature of the cognitive decline may make a patient more vulnerable to such a response in view of their reduced ability to adapt and cope with stress.

When a diagnosis is uncertain, doctors may decide not to alarm their patient unnecessarily and will not discuss the diagnosis even as a possibility. A doctor must consider the consequences of diagnosis on a patient's employment opportunities, pension, insurance and mortgage rights. It may also limit their access to health care as a result of prejudice from other professionals (Drickamer \& Lachs, 1992).

Clearly, the negative aspects of giving a patient the diagnosis of Alzheimer's disease must be considered carefully in the individual case but, taken in isolation, none is sufficient to support the practice of withholding information from patients. When doctors do not tell patients their diagnosis, they must be sure that this is not on paternalistic grounds or because it makes them uncomfortable to break bad news to the patients (Goldie, 1982).

\section{Conclusions}

There are many dilemmas surrounding the issue of whether or not to tell a patient with Alzheimer's disease of their diagnosis. There are a number of ethical, clinical and practical reasons why patients should be told, but it may not be appropriate in all stages of the illness and for all patients.

Doctors must appreciate their patients' wishes to be told about their diagnosis and provide them with the support and knowledge that allows them the dignity to come to terms with their illness and be involved in plans about their current and future healthcare.

\section{References}

BURNS, A. \& HARRIS, J. (1996) Ethical issues in dementia. Psychiatric Bulletin. 20. 107-108.

Clafferty, R. A., Brown, K. W. \& McCaBe. E. (1998) Under half of psychiatrists tell patients their diagnosis of Alzheimer's disease. British Medical Joumal, 317, 603.

DRICKAMER, M. A. \& LACHS, M. S. (1992) Should patients with Alzheimer's disease be told their diagnosis? New England Journal of Medicine, 326, 947-951.

DEPARTMENT OF HEALTH (1992) Should patients with Alzheimer's disease be told their diagnosis? New England Journal of Medictne. 326, 947-951.

ERDE, E. L., NADAL, E. C. \& SCHOL, T. O. (1998) On truth telling and the diagnosis of Alzheimer's disease. Journal of Family Practice, 26. 401-406.

FEARNLEY, K., MCLENNAN, J. \& WEAKS, D. (1997) The Right to Know? Sharing the Diagnosis of Dementia. Edinburgh: Alzheimer Scotland Action on Dementia.

GILLIARD, G. \& GWILLAM, C. (1996) Sharing the diagnosis: a survey of memory disorders clinics, their policies on informing people with dementia and their families, and the support they offer. International Joumal of Geriatric Psychiatry, 11. 1001-1003.

GoLDIE, L. (1982) The ethics of telling the patient. Joumal of Medical Ethics, 8. 128-133.

KATZMAN, R. \& JACKSON, J. (1991) Alzheimer's disease: basic and clinical advances. Journal of the American Geriatrics Society. 39, 516-525.

LOVESTONE. S. \& HARPER. P. (1994) A genetic test for Alzheimer's disease? Psychiatric Bulletin. 18, 645.

Maguire, C. P., KirBy, M., Cohen, R. et al (1996) Family members' attitudes toward telling the patient with Alzheimer's disease their diagnosis. British Medical Journal. 313, 529-530.

Meredith, C., SYMONDS, P.. WeBster. L., et al (1996) Information needs of cancer patients in west Scotland: cross-sectional survey of patients' views. British Medical Joumal, 313, 724-726.

MEYERS. B. S. (1997) Telling patients they have Alzheimer's disease. British Medical Journal, 314, 321-322.

NovaCK. D. H. (1979) Changes in physicians attitudes toward telling the cancer patient. Journal of the American Medical Association. 241. 897-900.

OKEN. D. (1961) What to tell cancer patients. Joumal of the American Medical Association. 176, 1120-1128.

ORRELL, M. \& SAHAKIAN, B. (1995) Education and dementia. British Medical Journal. 310, 951-952.

RAANAN, G. (1994) Medical ethics: four principles plus attention to scope. British Medical Journal. S09. 184-188.

RICE, K. \& WARNER, N. (1994) Breaking bad news: what do psychiatrists tell patients with dementia about their illness? International Joumal of Geriatric Psychiatry. 9. $467-471$. 
ROGERS. S. L. \& FREIDHOFF, L. T. (1996) The efficacy and safety of donepezil in patients with Alzheimer's disease: results of a U.S. multicentre, randomised, double blind, placebo controlled trial. Dementia, 7, 293-303.

RohDE, K., PESKIND. E. R. \& RASKIND, M. A. (1995) Suicide in two patients with Alzheimer's disease. Journal of the American Geriatrics Society. 43, 187-189.
R. A. Clafferty, Clinical Research Fellow and Honorary Specialist Registrar, Department of Psychiatry, The University of Edinburgh. Kennedy Tower, Royal Edinburgh Hospital, Morningside Park, Edinburgh EH1O 5HF

\section{Evidence-Base Briefing: Dementia Claire Palmer}

The number of published papers on the subject of dementia is constantly rising and it is virtually impossible for clinicians to read everything available, let alone to

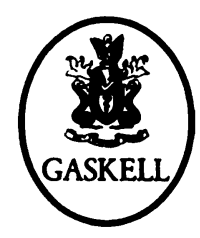
appraise it properly.

Evidence-Base Briefings (EBBs) are summarised collections of synthesised 'evidence' in a given topic area. This document on dementia attempts to encapsulate the best available evidence into a format which is quick and easy to use. Its main aim is to provide a checklist of appraised evidence from which a clinician can easily obtain original documents. These documents can then be appraised (using the tool provided) and interpreted for the clinician's own practice. The evidence sources on which the EBB is based include research, guidelines and national guidance. The EBB includes full references to its source documents and details of further information resources to support evidence-based practice.

June 1999, Paperback, ISBN 190124235 8, £15.00

Available from Book Sales, Royal College of Psychiatrists, 17 Belgrave Square, London SWIX 8PG Tel +44 (0) 1712352351 (extension 146) $9.30 \mathrm{am}-2$ pm, Fax +44 (0) 1712451231

http://mww.rcpsych.ac.uk 